
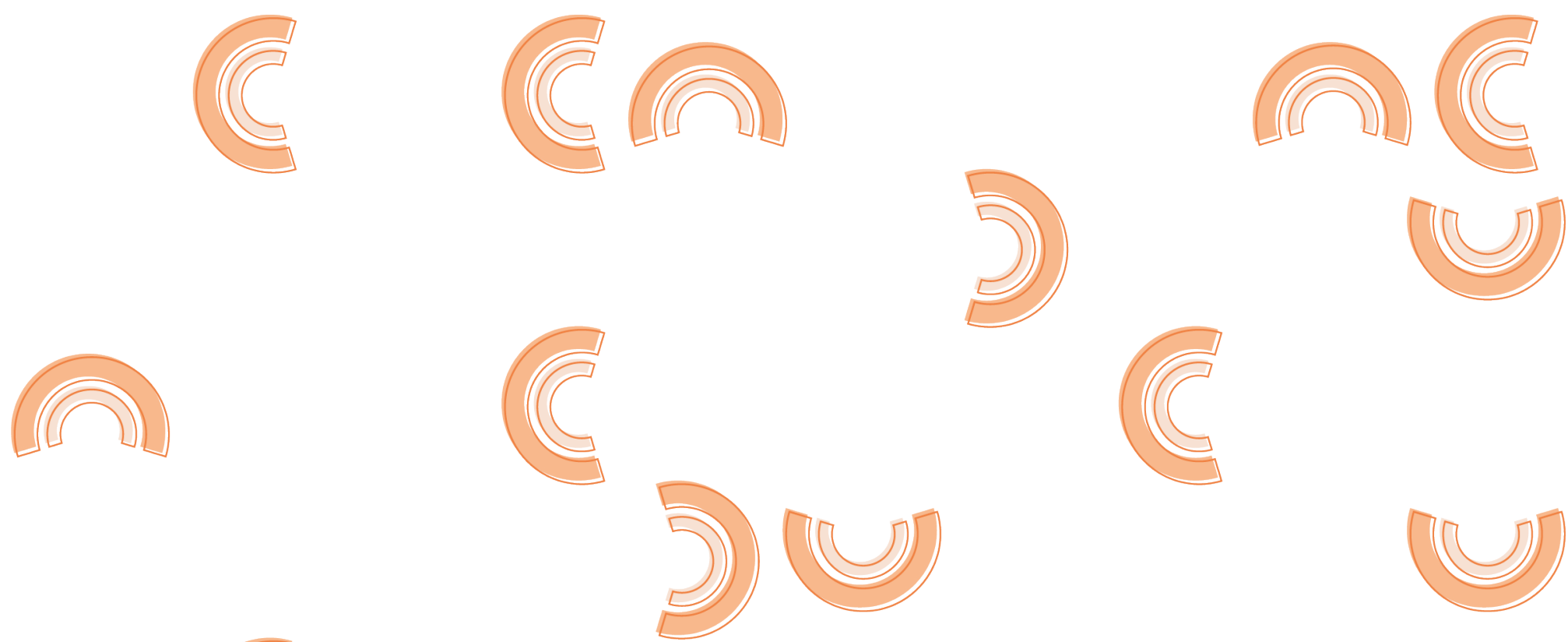

IDEIAS E CRÍTICAS

\title{
O CONFLITO COMO O FUNDAMENTO DO
}

DRAMA

CONFLICT AS THE BASIS OF DRAMA

\section{Prof. Paulo Ricardo Berton, Ph.D}

Professor Adjunto IV do Departamento de Artes e do PPCLit

Universidade Federal de Santa Catarina (UFSC)

E-mail: pauloricardoberton@gmail.com

\section{Bel. Aline de Fátima Pereira}

Graduanda do Curso de Artes Cênicas

Universidade Federal de Santa Catarina (UFSC)

E-mail: alineft.pe@gmail.com

\section{Bel. Waleska Georgiana de Oliveira}

Mestranda do PPCLit

Universidade Federal de Santa Catarina (UFSC)

E-mail:waleska.keka@hotmail.com 


\section{RESUMO}

A partir da definição de Hegel de que o gênero dramático se estrutura a partir da colisão entre duas vontades, são examinadas formas artísticas contemporâneas de grande sucesso junto ao público, para corroborar a importância do conflito em suas estruturas, quais sejam: o filme de animação, o filme de suspense e a telenovela.

Palavras-chave: Drama, Conflito, Filme de Animação, Filme de Suspense, Telenovela.

\section{ABSTRACT}

From Hegel's definition that the dramatic genre is structured from the collision between two wills, contemporary artistic forms of great success with the public are examined to corroborate the importance of the conflict in its structures, namely: the animated film, the thriller and the soap opera.

Keywords: Drama, Conflict, Animated Film, Thrillee, Soap Opera. 


\section{O CONCEITO DRAMÁTICO DE CONFLITO}

O propósito de cativar a atenção do espectador em se tratando de arte não é uma característica do sistema capitalista. Qualquer manifestação artística necessita a atenção do seu público para que seu propósito, seja ele de mero entretenimento, de conscientização crítica, de uma provocação à la 'épater la bourgeoisie' ou de transformação espiritual, se realize. E esta atenção se concretiza no momento em que o público frui aquilo que escuta ou assiste, demonstrando um prazer estético. Bertolt Brecht ${ }^{1}$ já dizia com todas as palavras que: "Mesmo que aceitemos tal extensão (do conceito de teatro) ainda precisamos dizer que a função mais universal da estrutura teatral é a de conceder um prazer. É a função mais nobre que encontramos para a arte do teatro" (BRECHT, 1964, p.180, tradução nossa) ${ }^{2}$.

Quando estamos tratando do drama, que é um gênero literário que só se completa no momento da encenação teatral, uma vez que ele é escrito para que o texto seja falado por atores e não simplesmente lido, como na poesia ou na narrativa, a preocupação com este 'prender a atenção do espectador' se torna uma condição sine qua non para a recepção da obra. Num espetáculo teatral, o que se estende para as outras artes cênicas ${ }^{3}$, se pressupõe que o público irá permanecer até o final, diferentemente de um livro ou de uma música que podem ser interrompidos na metade ou então, se retroceder na sua leitura ou escuta. No teatro, que é a concretização do drama, não.

Para tanto, os teóricos do drama estabeleceram alguns conceitos basilares para definir e diferenciar o drama de outros gêneros literários. Estes conceitos tratam de elementos que irão cumprir esta função de manter a atenção do espectador teatral e garantir a fruição estética como um pré-requisito para
1 Importante encenador teatral, autor dramático e teórico teatral alemão e principal representante do chamado 'teatro épico' a partir dos anos 20 do século XX.

2 Even if we did accept such an extension we should still have to say that the 'theatre' set-up's broadest function was to give pleasure. It is the noblest function that we have found for 'theatre'.

3 Que são as artes que acontecem no momento presente na frente do público, como o teatro, a ópera e a dança, por exemplo. 
qualquer que seja a intenção do autor do texto dramático e da sua posterior encenação. $O$ conceito de que iremos tratar neste artigo é o de conflito.

Etimologicamente, a palavra drama deriva do grego - draó - e significa ação (PAVIS, 2007, p.109). Desde Aristóteles é comum definir drama considerando-se uma ação una, permeada de nexo causal e um conflito ascendente determinado pela "curva dramática", que possui tempo e lugar determinados para ocorrer com os personagens. Muitos teóricos do teatro concordam que um dos elementos caracterizadores do gênero dramático é a ação, uma vez que, uma peça ao ser encenada não apenas conta uma história, através de personagens ou de um narrador, como no gênero épico, mas a mostra ao público no momento de sua ocorrência. Ainda que a ação aconteça em flashback, quando uma personagem no agora rememora seu passado, a ação é presentificada através da lembrança revivida (ROSENFELD, 1985). O gênero dramático evoca o passado, adianta o futuro e coloca ambos no presente (ROSENFELD, 1985).

Renata Pallotini (1988) questiona a ação como o único elemento responsável pela definição do drama e como exclusiva definidora da natureza teatral. Neste estudo sobre o drama, a autora resgata o pensamento de Georg Wilhelm Friedrich Hegel (1770 - 1831), para quem a ação só tem sentido se por trás dela houver um conflito que progrida dramaticamente, ou seja, evolua, atinja seu ponto máximo e se encaminhe para a resolução no decorrer da trama. O conflito foi mencionado pela primeira vez na história da teoria do drama por Hegel. Na concepção hegeliana de drama é necessário que haja um objetivo a ser cumprido, fruto da vontade de um personagem que sabe o que quer e faz algo por isso, e ainda deve haver obstáculos para a realização desse objetivo (PALLOTINI, 1988).

Pallotini (1988) no decorrer de sua pesquisa sobre a dramaturgia realiza um levantamento das considerações acerca do gênero dramático segundo diversos autores, sendo que alguns deles, como Ferdinand Brunetière (1849 1906) e John Howard Lawson (1849 - 1977), enfatizam, na esteira de Hegel, a importância do conflito na estrutura dramática. Ferdinand Brunetière ressalta que o que caracteriza o drama é o exercício de uma vontade. São as vontades das personagens que conscientes dos meios que empregam para atingirem seus fins se deparam com os obstáculos que promovem o andamento da ação, logo, o drama está estruturado a partir de um conflito de vontades. Já Lawson afirma que o conflito que move a ação dramática deve ser um conflito social. Segundo ele (1949), o drama coloca pessoas contra pessoas, indivíduos contra grupos, grupos contra outros grupos, indivíduos ou grupos contra forças sociais ou naturais. E estes conflitos para serem dramáticos devem alcançar um ponto de crise. As conclusões de Lawson se fundamentam no conceito de crise 
como um ponto de evolução máxima do conflito, o ponto no qual uma nova situação há de ocorrer para dar continuidade ao argumento dramático.

Para estes três autores, o elemento propulsor da estrutura dramática é, então, o conflito. É importante ressaltar, como visto em Hegel, que a ideia do conflito no drama está vinculada à da intencionalidade. Dessa forma, o conflito é de vontades que podem partir tanto de contradições internas do protagonista (conflitos internos), como da oposição de outra personagem ou de um grupo (conflitos externos).

O conflito é a tensão produzida pela presença simultânea de vontades contraditórias, ele constitui a essência do drama e é caracterizado pelo choque de interesses. O conflito pode ser de várias espécies — entre o bem e o mal, ideias e verdades morais ou religiosas, o conhecido e o desconhecido, princípios de Direito, entre outros. A importância do conflito está no fato de ser a partir dele, ou em decorrência dele, que ocorre a progressão da estrutura dramática, da narrativa e o consequente envolvimento do público.

Enquanto condição sine qua non, o conflito tornou-se marca registrada do gênero dramático (PAVIS, 2007, pp.67-68). Algirdas-Julius Greimas (1917 1992), responsável pela proposição do modelo actancial, considera que existem várias forças que impulsionam o jogo dos actantes como: o amor, o fanatismo religioso ou político, a avareza, o desejo de poder ou de autoridade, entre outros. O modelo proposto pelo autor é um modelo esquemático de compreensão da narrativa (o qual se adapta às peças de teatro), cuja premissa principal é de que a narrativa é um fluxo impulsionado por um actante que opera movido por um desejo intenso (uma busca obstinada, uma necessidade) (UBERSFELD, 2005). No diagrama do modelo actancial de Greimas, há um sujeito $S$, motivado por um destinador $D 1$ e visando o favorecimento de um destinatário $D 2$, que busca um objeto $O$, contando com o auxílio de um adjuvante Ad e a obstaculização de um oponente Op (UBERSFELD, 2005). Este modelo privilegia a compreensão da personagem dramática que atua ativamente na concretização de uma tarefa motivada por um desejo que se depara com um obstáculo. Cada personagem de uma narrativa, peça teatral, a cada instante em que se faz presente na cena, deve ser compreendida como um actante-sujeito $(S)$ impulsionado por um desejo que o impele a um objeto $(O)$. Portanto não existe personagem dramático que não manifeste um desejo ou que não opere a busca desse desejo em forma de ação.

$\mathrm{Na}$ dramaturgia, o conflito estabelece a dialética entre as personagens e as ações. Origina a personagem e a sua oposição. Os episódios só fazem sentido quando relacionados ao conflito principal, que tece a intriga. Por esse motivo os roteiristas admitem o conflito como o cerne da ação. Todo drama é conflito. 
Sem conflito não há personagem; sem personagem, não há ação; sem ação, não há história; e sem história não há roteiro, afirma Syd Field (2001, p.5), conceituado roteirista. O drama seja ele um filme de suspense, de aventura ou qualquer outra forma possível, necessita de impacto, da luta por alguma coisa.

A hipótese central deste artigo sugere que o conflito éa categoria estruturante do drama, presente nos diferentes meios, seja ele teatro, telenovela ou filme. O conflito centraliza a estrutura dramática e compõe os filamentos que encadeiam as ações das personagens; este elemento determina os episódios que desenham sequências lógico-temporais e concatenam os enredos das histórias.

Diante do exposto o presente estudo pretende elucidar através da análise de filmes de animação, filmes de suspense e telenovelas, gêneros de grande apelo popular, a persistência da estrutura dramática nos dias atuais e a sustentação dessas estruturas através do conflito. Uma vez que não existe drama em uma história sem conflitos. São os conflitos que impulsionam a história, e a resolução deles é que prende a atenção do espectador.

\section{O CONCEITO DRAMÁTICO DE CONFLITO EM FILMES DE ANIMAÇÃO}

Uma das formas artísticas dramáticas mais bem-sucedidas na atualidade é, sem dúvida, o filme de animação. Uma curta matéria no The New York Times

Style Magazine de quatro anos atrás mostra a sua posição de destaque na indústria do entretenimento:

Adeus, Capitão América: Animação, não filmes de super-heróis, são os novos pesos-pesados nas bilheterias. Precisa de provas? Considere os antípodas financeiros e críticos deste verão, "Quarteto Fantástico" e "Divertida Mente". Enquanto o passeio de ação ao vivo da Fox, sobre uma equipe de mutantes notavelmente bem-sucedidos para salvar o mundo, chegou a um cenário de perda quase histórico, o último foi um grande sucesso - um filme familiar inteligente e irresistível que não foi apenas o ponto alto criativo do ano, mas também o oitavo esforço consecutivo da Pixar para arrecadar mais de US $\$ 500$ milhões em todo o mundo. Mas não é apenas um retorno estonteante de ingressos que está impulsionando o gênero: potencial de licenciamento quase ilimitado (veja: "Minions", da Universal, sem mencionar o "Frozen" da Walt Disney), juntamente com o potencial expandido no mercado internacional. O mercado - juntamente com horários flexíveis e pagamento generoso para dubladores de celebridades - fizeram da animação uma das únicas apostas seguras em Hollywood ${ }^{4}$ (MALONE, 2015, tradução nossa).
4 Move over, Captain America: Animated features, not superhero films, are the new heavy-lifters at the box office. Need proof? Consider this summer's financial and critical antipodes, "Fantastic Four" and "Inside Out." While Fox's live-action outing, about a crew of remarkably good-looking mutants out to save the world, sputtered to a near-historic loss, the latter was a runaway success - a brainy, irresistible family film that was not only the year's creative high-water mark but also the eighth consecutive Pixar effort to gross over $\$ 500$ million worldwide. But it's not just eye-popping ticket returns that are bolstering the genre: Near-limitless licensing potential (see: Universal's ubiquitous "Minions," not to mention Disney's merchandising juggernaut "Frozen") coupled with expanded potential in the international market - along with flexible hours and generous pay for celebrity voice actors - have made animation one of the only sure bets in Hollywood. 
Este vigor financeiro e simbólico, traduzido por bilheterias e o espraiamento da marca através de produtos secundários, somente é possível se o filme em si atrair o público. E para tanto, a responsabilidade do sucesso fica sob responsabilidade dos elementos dramáticos que tornam o embate entre as emoções da menina Riley, do filme Divertida Mente, algo quase encantatório. Em outras palavras, o grande demiurgo do filme de animação é

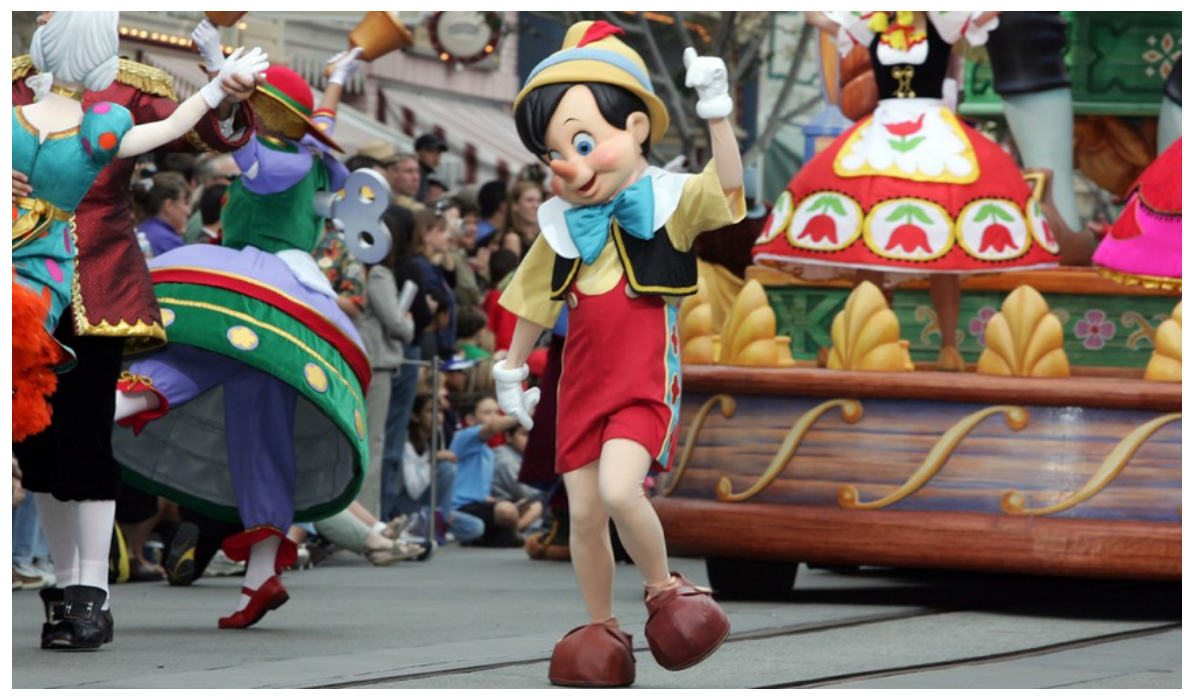
quem escreve o roteiro, ou seja, quem conta a história.

Os dois filmes de animação escolhidos para análise neste artigo são:

Figura I Pinóquio em desfile na Disneyworld (Mashable, 2018)

Pinóquio (1940) e Procurando Nemo (2003). Procurando Nemo é considerado o filme de animação mais rentável de todos os tempos arrecadando 70,3 milhões de dólares quando de sua estreia em 2003. E por fim, Pinocchio, um clássico da Disney, muito mais antigo e com técnicas de animação bem menos sofisticadas, que põe em cheque a primazia do novo e do contemporâneo sobre as histórias infantis clássicas, bastando observar como a personagem se mistura a outras bem mais recentes nos parques de diversões da Disney espalhados pelo mundo.

Em cada um destes filmes irá se verificar o quanto um conflito bem construído e uma trama amarrada conseguem cativar e manter o espectador atento, do começo ao fim.

\section{PINÓQUIO}

Seguindo a ideia hegeliana do conflito como um embate entre duas vontades, ou conforme Pallotini: "da colisão entre os objetivos dos personagens" (1988, p.13), nesta adaptação cinematográfica de 1940 do romance de Carlo Collodi intitulado Le Avventure di Pinocchio. Storia di un Burattino, lançado em 1881 na Itália, já nos deparamos com uma estrutura curiosa. Para Hegel, a personagem para ser dramática precisa possuir três características: ter uma consciência, ter uma vontade muito forte e estar ciente das consequências dos seus atos. Pinóquio é um boneco, logo, apesar de terem lhe sido concedido movimentos autônomos pela Fada Azul, ele não consegue perceber o quanto ele ainda continua sendo manipulado pelas vontades alheias. Isto se torna problemático em relação a uma personagem dramática, uma vez que ela precisa querer muito alguma coisa e estar consciente do que pode acontecer com ela, 
mesmo optando por seguir rumo à catástrofe. Édipo, por exemplo, é advertido inúmeras vezes na tragédia escrita por Sófocles de que sua obsessão por descobrir a causa da peste em Tebas pode levá-lo à ruína, mas mesmo assim, ele decide continuar sua investigação. Pinóquio é um mero joguete nas mãos dos 'vilões' do filme: Stromboli, João Honesto e o Cocheiro, cujo apetite capitalista pelo lucro e fortuna fácil necessita da exploração da inocência de seres menos dotados ou quase ausentes de consciência, como crianças e bonecos.

Logo, a personagem mais adequada para ocupar a posição de protagonista da trama, apesar de estar ausente dela por uma boa parte, é o velho marceneiro Gepetto, que solitário em sua cabana nos alpes europeus, sonha em ter uma companhia humana na sua rotina diária, além da presença do seu gato Fígaro e do peixe Cleo. A escolha do protagonista é sempre uma decisão arriscada, uma vez que envolve muitas variáveis, quantitativas (como o número de cenas em que aparece, o número de falas, o quanto as outras personagens falam dela, etc...) e qualitativas (o quanto ela contribui para a evolução da ação dramática). Pinóquio claramente não quer muito alguma coisa, sucumbindo facilmente aos prazeres mundanos da celebridade, da gula, do jogo, numa clara condenação puritana aos vícios em detrimento das virtudes exigidas pela Fada Azul para que Pinóquio alcance a posição de um 'menino de verdade': coragem, sinceridade e altruísmo. Por isso, nos parece que Gepetto poderia se encaixar nesta função, até porque o filme se inicia contando o contexto dele e o sonho de que Pinóquio, seu brinquedo predileto, fosse seu filho.

Então, poderíamos construir o modelo actancial de Gepetto da seguinte forma:

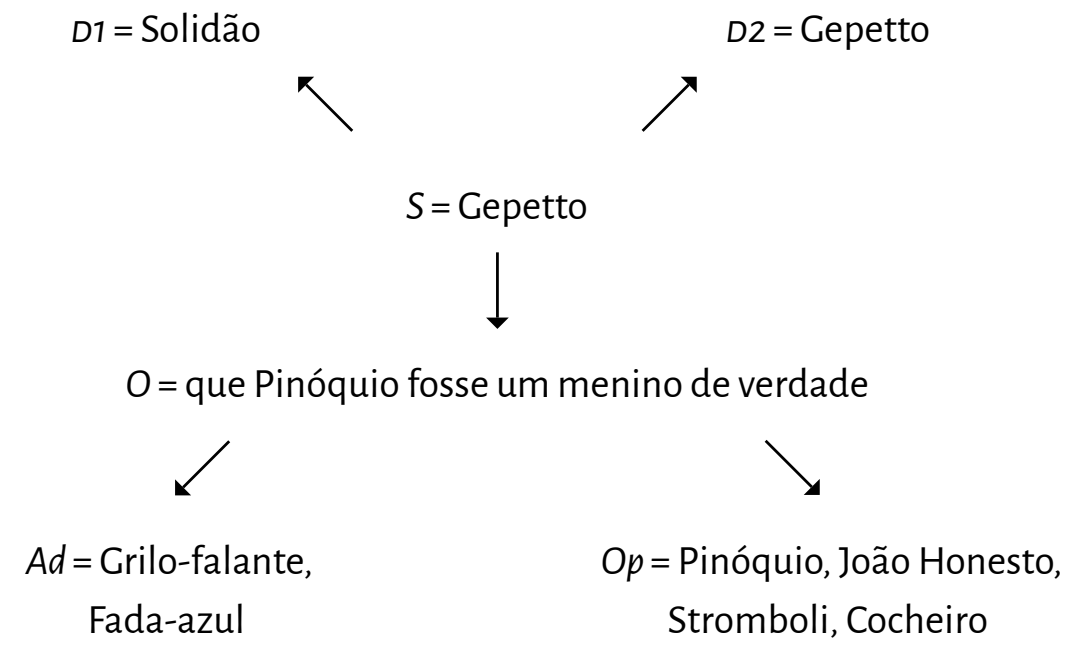

Gepetto quer muito (vontade forte) que Pinóquio se transforme num menino de verdade (para aplacar a sua solidão). Quem naturalmente se beneficiaria 
caso este objetivo fosse alcançado seria o próprio Gepetto. Curiosamente, Gepetto não é capaz de alcançar este objetivo sem o auxílio de forças sobrenaturais como a Fada Azul, que para Mayerson: "é um Deus ex Machina, ou máquina dos deuses. Gepetto expressou seu desejo de que Pinóquio seja um menino de verdade, mas a única maneira pela qual a história pode avançar é através da intervenção sobrenatural"5 (2007, tradução nossa).

É esta personagem que dota o boneco Pinóquio de movimentos (numa aproximação com a Esfinge no mito de Édipo). Além dela, existe outra personagem fantástica que vem a ser o Grilo Falante, que funciona como a consciência de Pinóquio. O elemento crucial para a categorização de uma personagem como dramática, na trama é separada do corpo da própria personagem, mostrando mais uma vez que Pinóquio não a possui. O tom fantástico do romance obriga a presença deste tipo de ajudante, caso contrário a história não se desenvolveria. Como opositores à consecução do objetivo de Gepetto estão Stromboli, o bonequeiro, João Honesto, um oportunista sempre à busca de alguma vantagem financeira fácil e o Cocheiro, um explorador de menores que os seduz levando-os a um lugar repleto de divertimentos, a maioria proibidos, chamado 'A ilha dos Prazeres' e com o excesso do vício os vê se transformarem em jumentos, que serão então utilizados por ele como animais de carga a custo zero. Estes três opositores afastam Pinóquio do seu desejo de se tornar um menino de verdade, já que as qualidades exigidas pela Fada Azul ficam cada vez mais distantes. Pinóquio, por sua vez, também é um opositor no modelo actancial de Gepetto, porque sem a sua consciência, não consegue discernir o certo do errado, conforme os preceitos da fada, e acaba pondo cada vez mais em risco o objetivo do seu pai postiço.

A dificuldade em analisar Pinóquio através das ferramentas do drama está no fato de ele não ter sido concebido inicialmente como tal. O elemento fantástico não fica à vontade numa estrutura dramática, uma vez que a personagem acaba não estando totalmente no controle de suas ações. A palavra protagonismo não designa apenas a personagem mais importante ${ }^{6}$ mas a capacidade desta e de todas as outras de levarem adiante a sua estratégia em busca da realização do seu objetivo. Por isto a necessidade de antropomorfização de figuras não-humanas, como animais e bonecos, para que estas personagens se enquadrem nos pré-requisitos de uma personagem dramática.

Originalmente um romance, o elemento diegético aparece claramente na personagem do Grilo-falante, que vai contando a história do marceneiro e de seu boneco, enquanto as cenas ilustram através de imagens o que está sendo narrado. O Grilo cumpre uma função épica de comentar a trama, naturalmente dentro da ideologia defendida pelos autores da adaptação, uma função $\mathbf{5}$ is a Deus ex Machina, or machine of the gods. Cepetto has expressed his wish for Pinocchio to be a real boy, but the only way the story can move forward is through supernatural intervention.

6 Deriva do grego protagonistes, onde protos significa principal ou primeiro e agonistes significa lutador ou competidor. 
bastante comum no drama e já conhecida desde a tragédia clássica grega. Esta ênfase na contação diegética aparece na ênfase dada à boca, como a parte do corpo que emite a palavra, o último elemento que Gepetto pinta no seu boneco preferido.

A boca também é sobressaltada através da baleia, que engole a 'família' Gepetto e depois os expele, incomodada com a fumaça causada pela metafórica queima da madeira dentro dela, provocada pela finalmente alcançada perspicácia de Pinóquio.

\section{PROCURANDO NEMO}

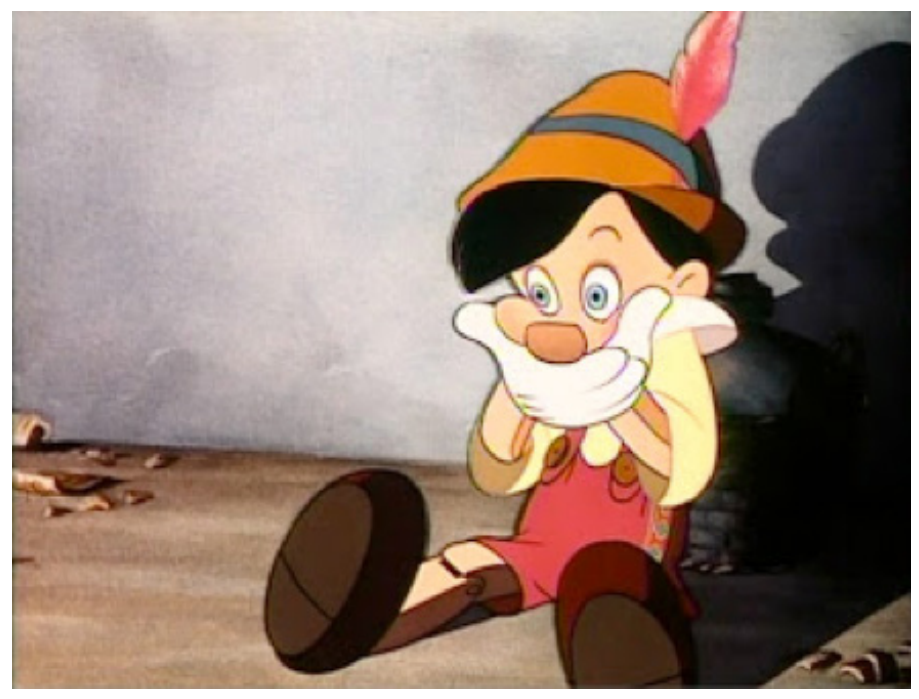

Se em Pinóquio a trama acompanha de perto as peripécias do 'filho' de Gepetto, deixando o sofrimento do bonequeiro em segundo plano, em Procurando Nemo (2003), uma co-produção entre as gigantes do ramo Disney e Pixar, ao Figura 2 Pinóquio se surpreende que consegue falar (Mayerson on Animation, 2007) mesmo tempo que seguimos a jornada de Marlin, o peixe-palhaço protagonista deste filme de animação computadorizada, também nos é mostrada a situação de cativeiro do seu filho Nemo num aquário de um consultório dentário. O ponto-de-ataque do filme se dá quando Nemo, no seu primeiro dia de aula, resolve rebelar-se contra a superproteção do pai, causa de vergonha perante os outros alunos-peixes, e se afasta de forma irresponsável do grupo, sendo assim colhido por uma rede de pescadores. O foco principal da trama passa a ser então a busca desesperada de Nemo pelo seu único filho, uma vez que todos os outros tinham sido devorados, juntamente com sua mulher, no início do filme. O tema da paternidade e o doloroso ingresso na vida adulta, quando passamos a nos responsabilizar pelos nosso próprios atos, reaparece neste filme. Curiosamente, tanto Pinóquio quanto Nemo são 'tragados' por forças malignas no momento em que saem da proteção do lar para a escola, a primeira instituição social com a qual a criança se depara. Nemo está muito mais próximo da ideia hegeliana de um sujeito ativo que quer muito alguma coisa e luta bravamente para alcançar este seu objetivo. Talvez os roteiristas de Hollywood tenham aprendido em sessenta e três anos a criar tramas mais ágeis e protagonizadas por agentes mais cientes de seus objetivos. Enquanto Marlin se depara com tubarões brancos, correntes marinhas que mais parecem montanhas russas, colônias de águas-vivas e baleias brancas que devoram tudo o que veem a sua frente (e aqui mais um parentesco possível entre os dois filmes ou quem sabe uma referência direta a uma produção anterior da Disney), Gepetto é esquecido pela trama e fica lamentando a perda do seu boneco-acrobata-cantante. O objetivo de Marlin é tão claro que o próprio título do filme remete a 
ele (apesar de que procurar é o que o peixe-palhaço faz e não o que ele quer, uma confusão muito comum para principiantes ao analisarem os modelos actanciais de uma dada trama). Nesta sua jornada, abundam opositores para impedi-lo ou atrasá-lo na procura do seu filho. Os maiores opositores, no entanto, estão longe dele: o dentista e sua sobrinha. Tendo ido parar num aquário de um consultório dentário, Nemo está prestes a ser

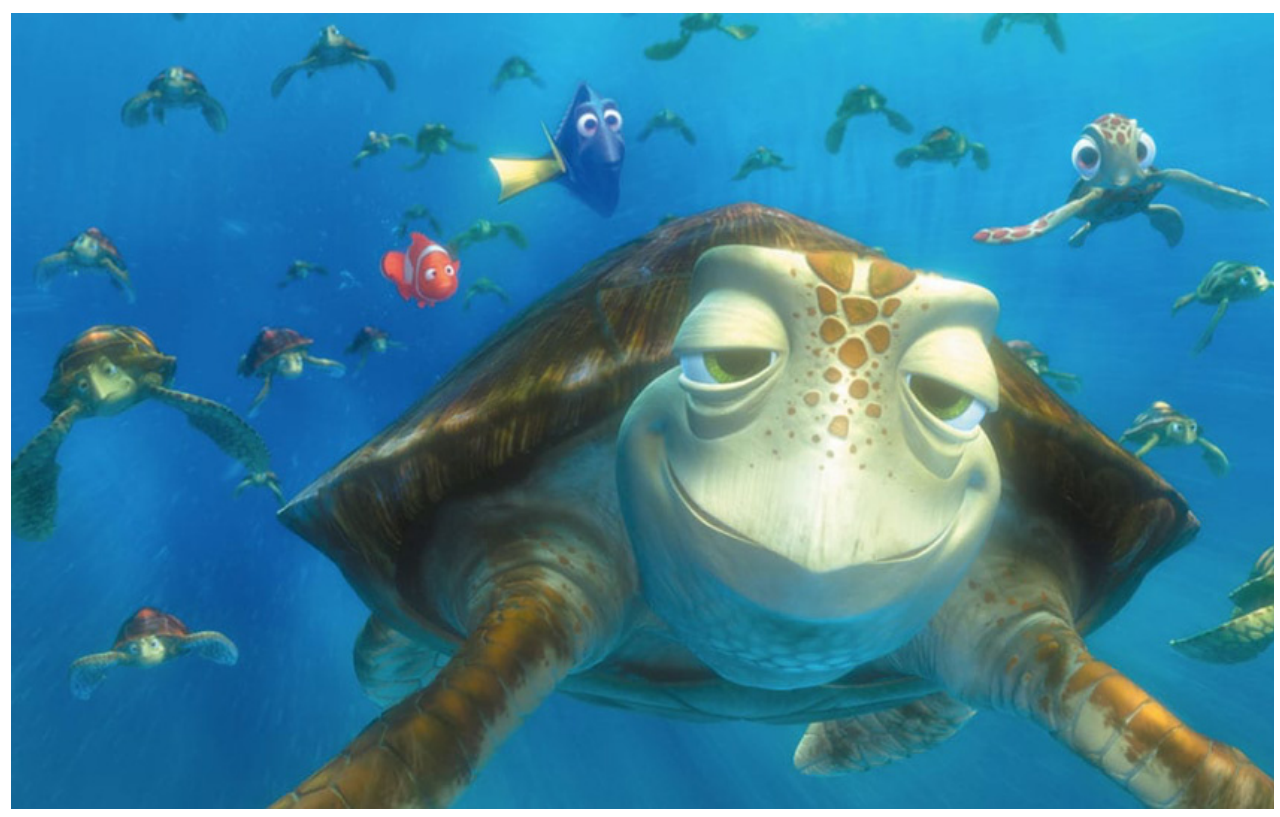
dado de presente a uma menina cruel e sádica, cujo passatempo é exatamente exterminar os peixes que ganha. Assim, a dificuldade em vencer os opositores se torna muito mais complicada para Marlin, uma vez que eles não estão no mesmo espaço físico. É uma corrida contra o tempo. Esta overdose de opositores é típica do cinema de ação de Hollywood. A necessidade mercadológica de se manter o público preso à trama sem nenhum vacilo obriga os roteiristas a povoarem os filmes com muitos opositores, como se estivéssemos literalmente numa montanha russa. No entanto, a função do modelo actancial que mais encanta neste Procurando Nemo é a da ajudante, ocupada pela adorável Dori, uma cirurgiã-patela, uma espécie típica de recifes de coral.

Dori sofre de perda de memória recente, e esta deficiência causa inúmeros quiproquós no filme. Entretanto será graças aos conhecimentos dela de baleiês, que Marlin consegue chegar à baía de Sidney, onde se encontra o seu filho, Nemo. Seu apelo para com o público foi tão grande que treze anos depois ela ganhou o próprio filme dela: Procurando Dori. O diretor do filme (e também de Procurando Nemo) justifica a razão de trazê-la de volta às telas:

Era simplesmente porque eu ficava assistindo Procurando Nemo e me preocupava com a Dori depois que terminava (...) Do ponto de vista do roteiro, eu pensava, ela não estava resolvida, e ela poderia facilmente simplesmente se perder do Nemo e do Marlin na cena seguinte e voltar a ser o que ela era7 (BUCHANAN, 2016, tradução nossa).

Desta forma, um possível modelo actancial, a partir dos estudos de Greimas e Ubersfeld, seria:

Figura 3 Crush, a tartaruga-verde que conduz Marlin e Dori pela corrente da Austrália Oriental (Oh, my Disney, 2019)

7 "It was simply because I watched Finding Nemo and worried about Dory after it was over," he said. "From a writing standpoint, I thought, 'She's completely unresolved under the hood, and she could easily just lose Marlin and Nemo in the next scene and be back to the way she was." 


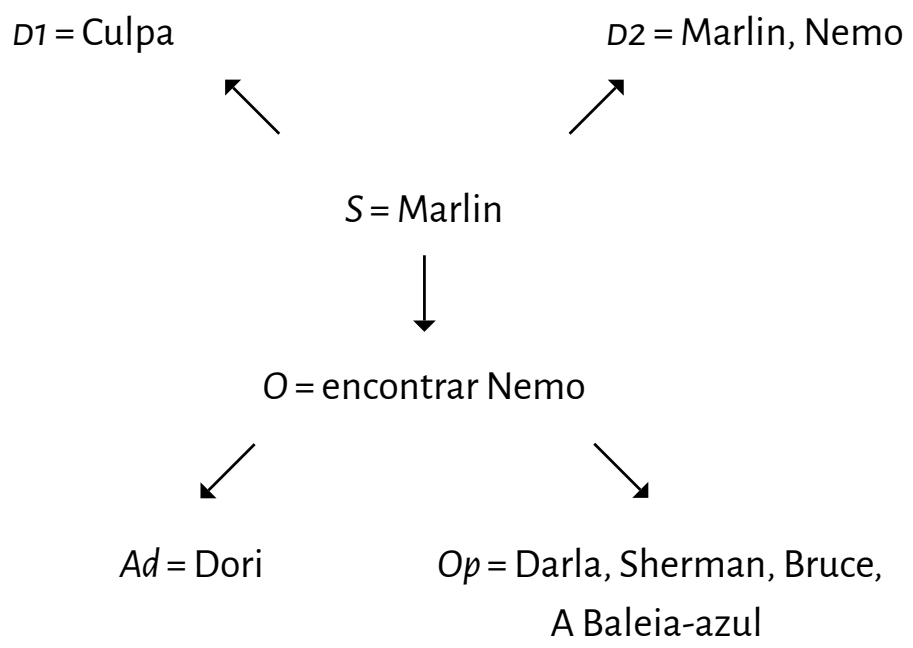

Curiosamente as crianças nos dois filmes ocupam sempre as funções do objetivo ou do opositor. Representam ao mesmo tempo a irresponsabilidade infantil e a malícia característica dos seres que ainda não desenvolveram formas de reprimir os seus instintos, estando mais próximas de seus ids do que de seus superegos, numa linguagem psicanalítica. Os protagonistas de Pinóquio e de Procurando Nemo não são crianças, até porque ambos o seriam de uma forma apenas antropomorfizada, pois se trata de um boneco de madeira e de um peixe. Quem conduz a nossa expectativa de reencontro são os seus pais, que ao perderem seus filhos para o 'mundo', tentam, cada um a sua maneira, Gepetto de forma mais derrotista e Marlin de forma mais incansável, retomarem aquilo que lhes parece ser de direito.

\section{O CONCEITO DRAMÁTICO DE CONFLITO EM FILMES DE SUSPENSE}

Os filmes, de maneira geral, expressam não só o olhar dos envolvidos em sua montagem, mas, indiretamente, evidenciam o imaginário de seus espectadores, pois a produção da obra fílmica antes de vir a contribuir na formação e reforço de hábitos culturais, leva em consideração a visão de seu público alvo, seu universo de referências, conhecimentos e expectativas.

O gênero cinematográfico de suspense designa um gênero de narrativa de ficção, no qual predominam as situações de tensão, provocando temor, surpresa ou eventualmente sustos no espectador, mediante os cortes repentinos. Ele instaura uma suspensão no contínuo da narrativa, com o intuito de conduzir o espectador a sofrer, ansiosamente, por meio da expectativa dos fatos que virão a seguir. Os cortes abruptos da ação narrada, por meio da parada, são feitos de modo que cresça e se intensifique a emoção a tal ponto que o espectador sinta, juntamente com a curiosidade, a angústia de querer adi- 
vinhar o desenrolar do conflito. O espectador é jogado em uma rede de emoções intensas, tão mais intensas quanto mais concentradas nos pontos de impacto. Assim, este tipo de obra sempre produz enunciados fílmicos que têm por base uma interação entre autor e público; possuindo um diálogo singular com o espectador que o guiará na sua experiência do contato com a obra fílmica (SILVA, 2011).

Grande parte dos enredos e personagens do cinema são transposições de clássicos da literatura, como o filme escolhido para análise nesse artigo Assassinato no Expresso do Oriente. O suspense dirigido por Kenneth Branagh, produzido em 2017 é uma adaptação do best-seller de Agatha Christie, famosa escritora britânica, lançado em 1930, onde a autora relata uma das aventuras de um dos mais famosos detetives do mundo Hercule Poirot.

A trama do filme é centrada no detetive Hercule Poirot, que enxerga o mundo através de um padrão de certo e errado, e faz uso dessa percepção para desvendar crimes. A imperfeição o incomoda e, muitas vezes isso torna sua vida insuportável. Para desvendar os mistérios, e chegar ao culpado, ele apenas precisa olhar com tranquilidade para o cenário do crime e descobrir o que não se encaixa. Cansado e tentando tirar férias, no entanto, incapaz de recusar equilibrar a balança da justiça, o detetive se envolve em um novo caso e precisa embarcar de última hora no trem Expresso do Oriente, para chegar ao local da investigação. Na noite seguinte, a bordo do Expresso do Oriente, a viagem é interrompida por uma nevasca que faz com que o trem descarrilhe e um assassinato acontece. Ratchett é morto em seu vagão e doze dos passageiros a bordo se tornam suspeitos. Bouc convence Poirot a usar suas habilidades para desvendar o crime cometido e o detetive inicia as investigações para desvendar o mistério do assassinato.

O protagonista do filme é Hercule Poirot, sua determinação é fácil, uma vez que, é através das suas decisões que ocorre a evolução da ação dramática, além de o detetive estar presente na grande maioria das cenas e interagir com todos os outros personagens. A bordo do Expresso do Oriente, Poirot interage com todos os passageiros, inclusive resiste à insistente aproximação de Edward Ratchett, que deseja contratá-lo para ser seu segurança particular, pois constantemente recebe ameaças de morte.

Quando o trem é impedido de seguir viagem, pois se descarrilha ao ser atingido por uma nevasca e o assassinato de Ratchett, com doze facadas acontece, o objetivo de Poirot fica evidente. O detetive deseja desvendar o mistério do assassinato e usa de todas as suas habilidades para alcançá-lo, mesmo colocando sua vida em risco. O fato o configura como um personagem dramático em concordância com a ideia hegeliana, para quem o personagem para 
ser dramático necessita possuir uma vontade consciente muito forte e estar ciente da consequência de seus atos (PALLOTINI, 1988).

Embora no início Poirot mostre-se hesitante em desvendar o mistério do assassinato, pois se encontra cansado após muitos anos de trabalho sem férias, Bouc o convence a investigar o caso, apelando para a personalidade do detetive, que não consegue deixar a balança da justiça sem equilíbrio, e que um inocente seja condenado e enforcado pela polícia. Demonstrando aqui um de seus conflitos internos.

Bouc é o único ajudante de Poirot na trama, auxiliando o detetive a desvendar o crime, pois deseja que o caso seja solucionado, uma vez que, tem interesse em manter sua reputação porque foi designado pelo tio, dono do Expresso do Oriente, a coordenar a viagem sem problemas.

O detetive é responsável por toda condução da ação, ele inicia a investigação entrevistando cada um dos passageiros, tentando descobrir o culpado através das imperfeições ou discordâncias em seus depoimentos. No entanto, o fato dos suspeitos mentirem para ele durante as entrevistas dificulta o detetive a atingir seu objetivo, configurando-os como seus principais opositores, instaurando-se assim o conflito externo do protagonista que faz com que a ação progrida.

Os doze passageiros podem ser identificados como um coro de personagens cujo único objetivo é matar Ratchett, motivados pela vingança, e para não serem descobertos, plantam pistas falsas e mentem ao detetive, desviando-o dos culpados, eles mesmos. O modelo actancial de Poirot pode ser descrito da seguinte forma a partir dos estudos de Greimas e Ubersfeld:

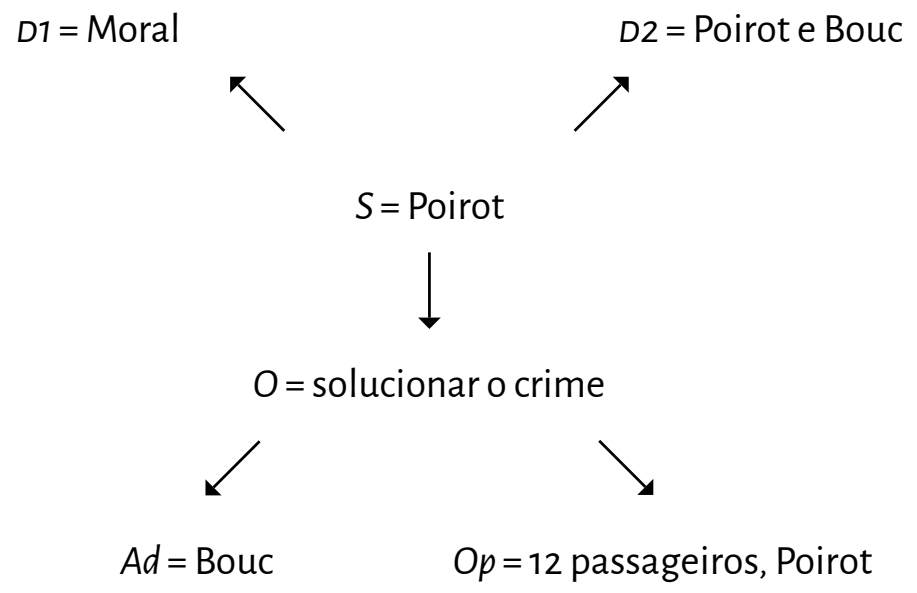

Quase ao final do filme, ao solucionar o caso, quando o detetive entende o cerne do mistério, as convicções de Poirot entram em choque e ele se depara 
com um dilema moral. Poirot descobre que o assassinato de Ratchett, pelos doze passageiros, está relacionado ao caso da família Armstrong, na qual Daisy Armstrong foi morta por Cassetti, antigo nome de Ratchett. O detetive conta a Bouc que na época do caso dos Armstrongs foi convocado para solucioná-lo, mas que quando chegou ao local para iniciar o trabalho, era tarde demais, a mãe da criança, Sônia Armstrong havia morrido e o pai, John Armstrong, se suicidado. O detetive, então questiona a si mesmo se o assassinato de uma inocente (Daisy Armstrong) pode justificar outro, o de seu assassino (Ratchett). Em uma carta ao falecido John Armstrong, pai de Daisy, narrada pelo próprio protagonista, Poirot demonstra a origem de seus conflitos internos que está relacionada ao seu entendimento da vida e dos seres humanos, como efetivamente enxerga o mundo: "Querido John, agora posso responder sua carta, pelo menos com os pensamentos e sentimentos no coração e espero que em algum lugar esteja me ouvindo. Agora descobri a verdade sobre o caso e é profundamente perturbador. Eu vi a fratura da alma humana. Tantas vidas destruídas, tanta dor e ódio dando lugar ao veneno da dor profunda, até um crime se tornar muitos. Sempre quis acreditar que o homem é racional e civilizado. Minha própria existência depende dessa esperança, de métodos e pequenas células cinzentas. Mas agora, talvez, tenha me questionado, ouvir, ao invés disso, meu coração".

Percebe-se no discurso de Poirot feito aos passageiros, além do descrito na carta, a presença de um acontecimento inesperado. O detetive demonstra que o caso da família Armstrong afetou outras doze vidas: amigos, funcionários e parentes que amavam a família Armstrong, e que precisavam de um acerto de contas para seguir em frente. Assim, contrariando sua própria natureza, a de não mentir, Poirot mente aos policiais e inocenta os assassinos dando a eles uma segunda chance.

O protagonista atinge seu objetivo, desvenda o mistério do assassinato de Ratchett, no entanto é incapaz de entregar os culpados.

\section{O CONCEITO DRAMÁTICO DE CONFLITO EM TELENOVELAS}

Ao me propor a analisar uma telenovela, inicio este parágrafo explicando um pouco sobre sua trajetória. A primeira telenovela nacional é feita e exibida em 1951, e esta forma surge como um desenvolvimento das novelas de folhetim e radionovelas, que faziam grande sucesso no país há um tempo. Esse novo jeito de contar esses dramas trouxe um impacto não somente no Brasil, mas em outros países da América Latina, que passaram a apostar no gênero.

Em 1980, com o mercado já mais estruturado, e a ascensão significativa de produções nacionais pela Rede Globo, outras emissoras também resolvem 
arriscar produzindo ou exportando. O SBT, para competir e acompanhar o que vinha a ser o tão aclamado sucesso destas, resolve focar nas produções latinas, que também estavam tendo grande adesão em seus países. E a partir disso, o que viriam a ser clássicos para a população, tanto quanto as telenovelas nacionais, vão ganhando espaço na casa do povo brasileiro.

Pensando nesse sucesso que essas produções tiveram não apenas fora, mas principalmente no Brasil, é que elenco uma delas para hoje abordar um pouco sobre como isso ocorreu.

Maria do Bairro é uma telenovela mexicana, criada e exibida em 1995 pela emissora "Canal de las Estrellas", com produção da Televisa, uma das grandes parceiras por trás das telenovelas de relevância do país. A trama seria a história de uma jovem periférica catadora de lixo, que ao perder sua madrinha, recebe a ajuda de um padre local e consegue um emprego de faxineira com uma família abastada. O conflito surge quando sua posição social, que diverge da família com a qual reside agora, dificulta uma boa relação entre todos. Além do embate entre ela e a sobrinha do casal residente, já que as duas disputam o amor do mesmo homem.

A proposta deste estudo é fazer uma análise da obra com o intuito de identificar como é exposto o conflito, o tema e a relevância desse tema para a novela e seu público.

A narrativa citada não passa longe de outras do seu gênero, o melodrama, onde a história é sempre carregada de inúmeras reviravoltas, emoções e descobertas que transformam qualquer tema em uma grande "montanha russa" de acontecimentos. Esse gênero em telenovelas sempre constrói uma narrativa sobre o cotidiano de um personagem, e a sequência de fatos que colaboram ou não para o desenrolar da trama.

Nas telenovelas, o melodrama é inserido e passa a conquistar públicos com sua temática, onde busca narrar a vida de alguém para que se reflitam aspectos fundamentais da realidade. Fazem então a representação de um cotidiano, e dividem núcleos entre vilões e mocinhos, para expor sentimentos, valores dentro de uma sociedade, e para que se faça um comparativo entre o ficcional e o cotidiano da vida real (uma busca pela aproximação do público). Boa parte das pessoas que assistem a uma ficção viveram situações de estruturas parecidas, sendo isso um dos artifícios que colabora com o engajamento na obra.

A telenovela nasceu logo depois do surgimento da televisão, conquistou o posto de produto de fabricação mais dinâmica da América Latina (...) Ocupa o horário nobre das TVs de diversos lugares em todo o mundo e é produzida continuamente em vários países: Brasil, México, Venezuela — os três maiores mer- 
cados exportadores do gênero na atualidade - Colômbia, Cuba, Chile, Peru e Porto Rico. (motTa, 2006. p. 35)

O ponto aqui, contudo, não seria falar sobre o desenvolvimento típico do melodrama, nem a aproximação do público com a vivência dos personagens em si, mas focando nossa análise na estrutura em si.

Pallottini verifica que Hegel trata o conflito como fundamental no drama, e a ação dramática como a causadora deste. "A finalidade de uma ação só é dramática se produzir outros interesses e paixões opostas". (PALLOTTINI, 1988. p. 11)

E ainda:

O interesse dramático só nasce da colisão entre os objetivos dos personagens. O que realmente produz efeito é a ação como ação, e não a exposição dos caracteres em si. A concentração de todos os elementos do drama na colisão (conflito) é que constitui o nó da obra." (PALLOTTINI, 1988. p. 13)

Ora, se é a ideia de conflito e de ação dramática que leva as personagens a outros interesses e outros conflitos, vamos expor algumas ações pontuais da obra a fim de verificar se elas se fazem presente.

O primeiro grande momento da telenovela inicia-se já no primeiro capítulo, após uma breve apresentação das principais personagens dos dois núcleos da telenovela (o do lixão e o da casa na cidade) vemos a protagonista perder sua madrinha e referência até então, e ao entrar em contato com o padre local, que por sorte acabava de conversar com um residente rico das proximidades, consegue resolver seu problema ao ter a oportunidade de trabalhar pra essa família. Na sequência, mudando de cena, ela chega ao local e é mal recebida, e então se montam dois polos distintos: a mulher (Vitória) e sobrinha (Soraya) do senhor que acabou de acolhê-la que a querem fora de lá, enquanto que o proprietário (Fernando) e uma governanta a querem ali. A princípio nenhuma motivação da protagonista (Maria) foi apresentada em relação a querer ficar, e logo que enxerga a situação contraditória, prefere ir embora. Ainda assim, ela permanece tempo suficiente para perceber que um dos moradores da casa é o jovem que ela tanto admira de longe (Luiz Fernando), e logo vê um motivo para então permanecer.

Mas o que temos aqui de ação dramática, se temos? Segundo Pallottini "No drama ou na farsa, o que nós pedimos ao teatro é o espetáculo de uma vontade que se dirige a um objetivo consciente dos meios que emprega". (PALLOTTINI, 1988. p. 20)

Considerando isso, o primeiro embate de vontades visto acontece entre o patrão e sua esposa, onde o primeiro sente a necessidade moral de adotar a moça, 
tratá-la como filha e lhe dar a educação e etiqueta que até então nunca teve, enquanto que Vitória, além de abominar as classes mais baixas, tem planos para a família aos quais sente que podem ser prejudicados por uma estranha.

É assim que se pode distinguir ação de agitação ou de movimentar... Será que agir é mover-se? Claro que não, e não haverá verdadeira ação a não ser por meio de uma vontade consciente de si, consciente dos meios que emprega para conseguir seus fins '. (PALLOTTINI, 1988. p. 21)

A princípio, as vontades de outros personagens, ainda que conflitantes também, não foram apresentadas frente a frente, porém a tensão de que isso hora ou outra acontecem já está estabelecida.

No decorrer dos próximos capítulos, temos claro o que cada personagem quer e como esses interesses dão continuidade ao enredo. A trama é dividida em três fases principais.

Na primeira, a questão social é o foco chave, e o grande conflito a se desenrolar é o relacionamento de Maria com Luís Fernando (filho de Vitória e Fernando). Este se desenvolve a partir de desejos opostos das personagens, já que enquanto a protagonista quer conquistar o jovem, ele por sua vez apenas deseja fazê-la acreditar que tem interesse para mais tarde magoá-la propositalmente. A todo momento surgem complicações para que Maria consiga de fato atingir seu objetivo, não apenas causadas pelo próprio Luís Fernando, como também por Soraya, sua então rival e outra residente da casa. Apesar do carisma da protagonista, e copiosas situações que a trama entrega ao público que indicam alguma reviravolta na situação amorosa, somente à medida que Maria vai melhorando sua educação e modos, e se encaixando no padrão da família, é que ela acaba conquistando a amizade e a confiança dos moradores e dos empregados da mansão, além da real afeição de Luís Fernando. Nessa reta final da primeira fase a disparidade entre Maria e Soraya vai diminuindo, demonstrando que o tempo ajudou a jovem a ser mais aceita no núcleo familiar, mas que de fato foi sua adaptação ao meio que lhe possibilitou um contato melhor com todos. O senhor vê seu objetivo cumprido, sua esposa aceita a situação. Terminamos a primeira fase de forma favorável à protagonista.

$\mathrm{Na}$ segunda fase, a protagonista é apresentada a um novo cenário. Agora está casada, seu nível social não é o mesmo de início, e até seus conflitos anteriores aparecem "solucionados" com a possível morte de Soraya. O tema social então é deixado de lado, e seguimos o desenvolvimento de seu casamento, que é apresentado como uma relação normal, mas que aos poucos se torna vítima dos ciúmes sem fundamento, e isso resulta em sua separação. O momento torna-se ain- 
da mais traumático quando Maria descobre que também está grávida. Luís Fernando, seu até então marido, a expulsa da residência em que viviam antes mesmo que ela possa revelar a gravidez, e vemos a protagonista passar quase todo esse segundo período em depressão, desamparada e sem perspectivas. Maria se encontra numa situação ainda mais severa do que a qual acompanhamos de início, de forma a perder sua sanidade mental por conta do abandono, sendo este momento retratado quando ela dá a luz a seu filho sozinha em um hospital público, e sai quase que na sequência do local com a criança para vagar nas ruas. Em determinado momento encontra uma senhora a qual lhe entrega seu filho. Passa ainda por inúmeras crises depressivas que a levam a uma internação, e esse cenário acaba levando à reconciliação do casal. Luís Fernando arrependido e extremamente triste pela perda do filho, resolve adotar uma menina, contra a vontade da própria Maria que se vê obstinada a encontrar seu primogênito.

Na terceira fase, o desenvolvimento da relação entre Maria e sua filha, Tita, seguem como um dos focos, já que elas não conseguem conviver bem. Paralelo a isso, temos a revelação que Soraya ainda está viva, e a apresentação do paradeiro do filho de Maria. Esses três núcleos se unem movidos por interesses que seguem se chocando: Soraya quer vingança, por ter seus objetivos frustrados há muito tempo. Maria quer conseguir trazer o filho de volta pra casa e reestruturar seu casamento (um pequeno desdobramento do objetivo da primeira fase, que era ficar com o rapaz). Luís Fernando quer que Maria deixe no passado o filho e aceite a nova realidade deles. A trama gira em torno das relações familiares mais do que nunca agora, já que por um lado temos os problemas latentes dessa estrutura e uma personagem a todo momento expondo e tentando resolvê-los, enquanto que de outro temos uma personagem que tenta a todo momento manter as aparências e apagar todos esses mesmos problemas. Suas ações, movidas por objetivos opostos, criam situações que retardam ambos de conseguirem o que querem.

O desfecho, como algo esperado no melodrama, se dá de forma espetacular e quase improvável, mas ainda assim feliz.

Maria consegue revelar a seu filho a verdade, e pouco tempo depois, Luís Fernando também acaba conhecendo-a também, e todo o momento é apresentado de forma impactante para reforçar posteriormente a união da família.

Soraya, em uma tentativa de matar Maria em um incêndio e concretizar enfim sua vingança, acaba morrendo carbonizada; e esse final ainda que inicialmente traumático, reverbera de forma positiva no núcleo familiar.

A telenovela finaliza com a união do casal principal novamente, a apresentação de casais secundários, e todo um ambiente agora não problemático em nenhum aspecto da vida das personagens. 
Cada ação tomada por Maria, ou em relação a ela, colocava a protagonista em situações que colaboravam para a transição do tema e o desenvolvimento de novas motivações para ela e outras personagens, demonstrando que cada "crise", segundo a definição de Archer, os levava a outra e assim sucessivamente: "Pode-se dizer que o drama é a arte das crises assim como a ficção é a arte dos desenvolvimentos graduais". (PALLOTTINI, 1988. p. 23)

Havia instaurado ali o conflito, já que "o objeto em oposição éo mais importante no drama." (ROSENFELD, 1985, p. 28), e este foi crucial para que novas situações fossem surgindo e colocando toda a história em curso.

$\mathrm{Na}$ temática, a telenovela inteira lida com questões bastante coesas e importantes. A todo momento temos ao fundo do desenrolar das vontades das personagens temas fortes, que foram e ainda estão em pauta no nosso meio, e que podem gerar identificação e/ou empatia.

Ainda que o charme do melodrama seja as grandes reviravoltas e romances impossíveis que se tornam possíveis, toda essa natureza não se sustentaria sozinha, não sem uma linha contínua de uma estruturação coerente que mantivesse ao menos plausível, dentro da proposta, o porquê de todos os acontecimentos seguirem como seguem. Nesse quesito, a telenovela vinga junto ao público ao trazer um jogo de poder e embate de vontades interessante e preciso, unido ao interesse e identificação com os problemas daquele grupo de pessoas.

As telenovelas são importantes para a população deste país porque reforçam seus valores, porque representam uma tradição e porque são uma das poucas opções de entretenimento gratuito com que conta a população. O México é um país criado sob a cultura do sofrimento, com uma população tradicionalista, conservadora e com muitas carências econômicas (CUEVA, 2006, tradução nossa). (apud MOTTA, 2006. p. 62)

Em termos numéricos, a telenovela cumpre seu papel em estruturação e temática, trazendo como resultado uma audiência de 16.82 pontos em sua estreia no Brasil em 19/02/97, sendo a meta apenas 7 pontos, e uma reprise de 18 pontos, onde a meta eram apenas 6 (isso em 12/11/07). Com esses números, ela leva o posto de segunda colocada no ranking das telenovelas mexicanas de maior audiência do SBT, perdendo apenas para A Usurpadora.

\section{REFERENNCIAS}

BECK, Kellen. Guillermo del Toro teams with Netflix for stop-motion take on

'Pinocchio'. Mashable. Disponível em: https://mashable.com/article/pi- 
nocchio-netflix-del-toro/\#vZBgk3JnHgq2. Acesso em 10 Dec 2018.

BRECHT, B. Brecht on Theatre. The Development of an Aesthetic. Ed. John Willet. New York: Hill and Wang, 1964.

BRUNETIÈRE, Ferdinand. The Law of Drama. In: Barret CLARK, ed. European

Theories of the Drama, New York: Crown Publishers, 1978, pp. 380-386.

BUCHANAN, Kyle. Why are Finding Nemo and Finding Dory such enormous

hits? Vulture. Disponível em: https://www.vulture.com/2016/06/why-are-the-finding-nemo-movies-such-big-hits.html. Acesso em 04 Jun 2019.

FIELD, Syd. Manual do roteiro: os fundamentos do texto cinematográfico.

Rio de Janeiro: Objetiva, 2001.

GREIMAS, Algirdas Julien. Semântica estrutural: pesquisa de método. Tradução

de: Haquira Osakabe e Izidoro Blikstein. São Paulo: Cultrix, 1973.

HEGEL, Georg.W.F. 'Dramatic Poetry'. Dramatic Theory and Criticism. Org. Bernard Dukore. Heinle: Boston, 1974.

LAWSON, John Howard. Theory and Technique of Playwrighting and Screenwriting. New York: Putnam's Sons, 1949.

LEMA, Michelle. 8 Signs you're obsessed with Finding Nemo. Oh, my Disney.

Disponível em: https://ohmy.disney.com/movies/2016/03/16/8-signs-youre-obsessed-with-finding-nemo/. Acesso em 04 Jun 2019.

MALONE, Clare. The Serious Business of Animated Films, by the Numbers.

The New York Times Style Magazine. 20 Oct 2015. p. 70.

MAYERSON, Mark. Pinochio, Part $3^{\text {a }}$. Mayerson on Animation. 2007. Disponível em: http://mayersononanimation.blogspot.com/2007/03/pinocchio-part-3a.html. Acesso em 10 Dec 2018.

MOTTA, Fernanda Gosser. Muito além da maquiagem carregada - 0 sucesso das telenovelas mexicanas no Brasil - A visão dos telespectadores. 2006. PALLOTTINI, Renata. Introdução à Dramaturgia. São Paulo: Ática, 1988.

PAVIS, Patrice. Dicionário de Teatro. Tradução: Maria Lúcia et al. São Paulo:

Perspectiva, 2007.

ROSENFELD, Anatol. O Teatro Épico. São Paulo: Perspectiva, 1985.

SILVA, Odair José Moreira da. O suplício na espera dilatada: a construção do gênero suspense no cinema. Tese (Doutorado em Semiótica e Linguística Geral) - Faculdade de Filosofia, Letras e Ciências Humanas, Universidade de São Paulo. São Paulo, 2011.

UBERSFELD, Anne. Para Ler o Teatro. Trad. José Simões Almeida Júnior (coord.). São Paulo: Perspectiva, 2005. 